\title{
Doppler Assessment of Aortic Ishtmus in Fetuses with Intrauterine Growth Restriction
}

\author{
Dr. Vijay K Verma ${ }^{1}$, Dr. Lovely Kaushal ${ }^{2}$, Mahrukh Khan ${ }^{3}$, Dr. Chandra Prakash Ahirwar ${ }^{3 *}$
}

${ }^{1}$ Associate Professor, Department of Radio-diagnosis and Imaging, Gandhi Medical College, Bhopal, Madhya Pradesh, India

${ }^{2}$ Professor Head of the Department, Department of Radio-diagnosis and Imaging, Gandhi Medical College, Bhopal, Madhya Pradesh, India

${ }^{3}$ Postgraduate Resident, Department of Radiodiagnosis and Imaging, Gandhi Medical College, Bhopal, Madhya Pradesh, India

DOI: $10.36347 /$ sjams.2020.v08i08.033

| Received: 16.08 .2020 | Accepted: 24.08.2020 | Published: 30.08.2020

*Corresponding author: Dr. Chandra Prakash Ahirwar

Abstract

Original Research Article

Objective: The aim of this study was to assess the flow velocity pattern of Aortic isthmus by Doppler imaging in fetuses with intra uterine growth restriction and to evaluate the association of Aortic isthmus Doppler parameters with intra uterine growth restriction. Introduction: Intra-uterine growth restriction (IUGR) is an important perinatal problem giving rise to increased morbidity and mortality in the fetus. Today, the main aim of fetal medicine is to prevent the occurrence of IUGR in high risk pregnancies and to appropriately manage those who are already affected with growth restriction. Knowledge of the fetal circulation and the compensatory changes during fetal hypoxia has helped us recognize the early signs of IUGR thus improving the prognosis of these high risk pregnancies. Doppler ultrasound provides this information effectively, which is not readily obtained from the other conventional tests of fetal well-being and can guide management decisions regarding the appropriate timing of delivery. Aortic isthmus (AoI) evaluation has been proposed as a potential monitoring tool for IUGR fetuses. It acts as a link between the right and left ventricles, thus forming an arterial connection between the two fetal vascular outputs positioned in parallel. So, any condition affecting fetal hemodynamics involving ventricular outflow or peripheral vascular impedance will affect the flow pattern through aortic isthmus. This study aims to assess the potential role of Doppler imaging of the AoI in at risk fetuses for early diagnosis of IUGR and to improve neonatal outcome. Material and methods: This was a descriptive comparative study which was performed on fetuses with suspected IUGR over a period of 18 months between March2016-September2017. 50 pregnant females of 24-40 weeks gestation who presented to OPD of Gandhi Medical College, Bhopal met the inclusion criteria. The fetuses who were small for gestational age and had associated maternal pathologies/risk factors along with oligohydramnios and abnormal umbilical artery Doppler waveforms (PI $>95^{\text {th }}$ centile for the gestational age) were considered as cases. The findings were compared with 50 controls who were selected randomly from the referred healthy pregnant females. Aortic isthmus Doppler parameters including velocities and impedance indices were assessed against normal reference ranges using both $95^{\text {th }}$ and $5^{\text {th }}$ centile as cut-off for abnormal values and were analyzed by using Unpaired t-test and Pearson's Chi-square test, as indicated. The Statistical analysis was performed in MS Excel spreadsheet using SPSS 19.0. The role of Aortic isthmus Doppler indices (PI, RI, PSV, EDV) and of a semi-quantitative indicator (Isthmic Flow Index, IFI) was assessed in predicting IUGR by using sensitivity, specificity and predictive values. P-value of $<0.05$ was considered to be significant. Results: Out of the 50 cases, 29 fetuses had IFI value less than 1 suggesting reversed isthmic diastolic blood flow and 21 had forward flow with IFI more than 1 . Mean RI and PI value in cases were $1.1354(+/-0.23)$ and 7.5392(+/- 8.80), respectively which was significantly higher as compared to mean RI of 0.8086(+/- 0.099) (P-value <0.0001) and mean PI value of 2.6154(+/- 1.064) $(\mathrm{P}$-value $=0.0002)$ in control cohort. Also, in case cohort, fetuses with retrograde flow through aortic isthmus had significant higher values of PI and RI as compared to fetuses with antegrade flow ( $\mathrm{p}$ value $<0.05$ ).Aortic isthmus PI value above $95^{\text {th }}$ centile was found in 33/50 (66\%) of cases. $7 / 50(14 \%)$ cases had retrograde AoI flow while the umbilical artery Doppler indices were normal. Conclusion: Our study suggests association of reversed diastolic flow through aortic isthmus with Intra uterine growth restriction. Also, PI and RI values of aortic isthmus in the IUGR fetuses were found to be significantly higher as compared to those in controls. 7/50 cases with retrograde flow through aortic isthmus had normal flow velocity profile in umbilical artery, suggesting that doppler indices of AoI can detect hemodynamic changes of IUGR prior to deterioration of umbilical artery Doppler waveforms. The data suggest a potential role of aortic isthmus Doppler imaging in diagnosing IUGR early in its course, thereby aiding clinicians in making timely decision regarding delivery. But, the data needs to be further assessed using longitudinal studies and randomized management trials to verify that delivery timing based on the Doppler findings can affect outcome of growth restricted fetuses. Objective: The aim of this study was to assess the flow velocity pattern of Aortic isthmus by Doppler imaging in fetuses with intra uterine growth restriction and to evaluate the association of Aortic isthmus Doppler parameters with intra uterine growth restriction.

Keywords: Doppler Aortic Ishtmus Intrauterine.

Copyright @ 2020: This is an open-access article distributed under the terms of the Creative Commons Attribution license which permits unrestricted use, distribution, and reproduction in any medium for non-commercial use (NonCommercial, or CC-BY-NC) provided the original author and source are credited. 


\section{INTRODUCTION}

Intra-uterine growth restriction (IUGR) is an important perinatal problem giving rise to increased morbidity and mortality in the growth restricted fetus. Today, the main aim of fetal medicine is to prevent the occurrence of IUGR in high risk pregnancies and to appropriately manage those who are already affected with growth restriction, before they have suffered from the adverse effects of hypoxia. Doppler ultrasound provides this information effectively, which is not readily obtained from the other conventional tests of fetal wellbeing and can guide management decisions regarding the appropriate timing of delivery. Knowledge of the fetal circulation and the compensatory changes during fetal hypoxia has helped us recognize the early signs of IUGR thus improving the prognosis of these high risk pregnancies [1].

Ultrasound has therefore become the gold standard [1] in the management of the growth-restricted fetus. Ultrasound utilizes the reflection of sound waves to evaluate soft tissue structure. Real time imaging has improved the use of ultrasound with dynamic images that are viewed instantaneously. Two modes of ultrasound are used: B-mode and duplex ultrasound. Bmode (brightness modulation) imaging utilizes real time imaging combined with a linear array of transmission beams to produce a two-dimensional image. Doppler ultrasonography is based on the physical principles of Christian Doppler (1803-1853), who described changes in sound frequency when reflected from a moving object. Pulsed-wave Doppler can be utilized to evaluate the direction and pulsatile nature of blood flow within vessels.

Aortic isthmus (AoI) evaluation has been proposed as a potential monitoring tool for IUGR fetuses. It is located between the origin of the left subclavian artery and the aortic end of the ductus arteriosus , and acts as a link between the right and left ventricles which perfuse the lower and upper body, respectively ,thus forming an arterial connection between the two fetal vascular outputs positioned in parallel [2]. So, any condition affecting fetal hemodynamics involving ventricular outflow or peripheral vascular impedance will affect the flow pattern through aortic isthmus [3, 4, 8-10].

Under normal conditions, the isthmic flow velocity waveforms have been shown to vary concomitantly with physiological changes in ventricular output as well as cerebral and placental vascular resistances, Fouron JC et al. studied the flow velocity profile of aortic isthmus in normal fetuses and found that the aortic isthmus has forward flow throughout the cardiac cycle and that the diastolic deceleration phase was gradual and smooth. After 20 weeks, an incisura appeared at end-systole that progressively increased. A brief reversal of diastolic flow was recorded after 30 weeks of gestation. In conclusion, the morphology of the Doppler flow velocity waveform of the fetal aortic isthmus changes with gestation $[9,4]$.

IUGR fetus is prone to hypoxia due to placental insufficiency. In placental insufficiency, compensatory changes in fetal hemodynamics promote blood flow towards left ventricle so as to supply adequate oxygen to fetal brain and heart [3]. Blood flow through aortic isthmus depends on cardiac output and net vascular impedance between cerebral and placental circulation. Increase in placental resistance causes reversal of isthmic diastolic blood flow even though the diastolic flow in umbilical artery remains forward. As growth restricted develops, there occurs decrease in isthmic absolute velocities. Reversal in umbilical diastolic flow is seen in severe condition, when fetus develops acidemia during which cerebral impedance decreases due to vasodilation leading to net retrograde flow in aortic isthmus. In cases with severe growth restriction, retrograde flow in aortic isthmus has been found as a strong predictor for adverse perinatal outcome [3].

Thus changes in aortic isthmus flow profiles can provide information about fetal cardiovascular status and predict outcome in intrauterine growth restriction [6]. Also, an increase in resistance to placental blood flow causes changes in aortic isthmic diastolic flow profile before any significant modification is observed in umbilical artery Doppler waveforms [4]. Aortic isthmus doppler thus may help in early diagnosis and thereby improving the management of sick fetuses.

\section{Material ANd Methods}

The study was conducted in the department of Radiodiagnosis, Gandhi Medical College Bhopal over a period of 18months (March2016-September2017) and included 50 pregnant females of 24-40 weeks gestation who presented to OPD with clinical signs of IUGR and met the inclusion criteria and were followed up for their birth weight. The findings were compared with 50 fetuses which were matched with respect to gestational age and had no known maternal risk factors, normal biometry and normal umbilical artery waveforms. Pvalue of $<0.05$ was considered to be significant with type I error of $5 \%$.

\section{Study Design}

Descriptive comparative study

\section{Study Area}

Department of Radiodiagnosis, Gandhi Medical College and Hamidia Hospital Bhopal

\section{Sample Source}

Pregnant females of 24-40 weeks gestation who presented to OPD with clinical signs of IUGR and was referred to the department of Radiodiagnosis for Ultrasonography and Doppler 
study. The study also includes 50 healthy controls which were selected randomly.

\section{Sampling Method}

Simple random sampling procedure was used. Subjects were selected from the attendance list of each day and were appointed dates as per their convenience.

\section{Inclusion criteria}

- Fetal Weight $<10^{\text {th }}$ percentile for the gestational age.

- Abdominal circumference $<5^{\text {th }}$ percentile for the gestational age.

- Umbilical artery pulsatility index (PI) $>95^{\text {th }}$ centile for the gestational age.

- Oligohydramnios.

The selection of cases was based on combination of clinical and sonographic parameters i.e h/o preeclemsia/previous IUGR/BOH, oligohydramnios, fetal weight $<10^{\text {th }}$ percentile for the gestational age and increased umbilical artery $\mathrm{PI}>95^{\text {th }}$ centile for the gestational age.

In addition, 50 healthy subjects were examined as control group. The healthy subjects had no $\mathrm{h} / \mathrm{o}$ preeclemsia/IUGR/BOH and had normal fetal biometry.

\section{Exclusion criteria}

- Twin or multiple gestations

- IUFD

7. Method of Collection of Data: Complete evaluation of subjects was done including -

- Clinical history and examination

- Ultrasonographic evaluation.

All subjects were enrolled with detailed oral and written consents. The study was approved by ethical and scientific committee of the institute.

\section{Instrumentation}

All examinations were performed in the ultrasound machines available in the department by using convex 3-5 MHz array transducer. Ultrasound examination including fetal biometry and Doppler study was done on fetuses with suspected IUGR who met the inclusion criteria.

\section{Fetal biometry}

Biparietal diameter (BPD), femur length (FL) and abdominal circumference (AC) were calculated and compared with reference values for estimation of gestational age and fetal weight.

- Biparietal diameter - The measurement was obtained from transverse axial plane of fetal head at the level of paired thalami and cavum septi pellucidi. The BPD is measured from the outer edge of cranium closest to transducer to the inner edge of cranium farthest from the transducer.

- Femur length - The femoral length was measured by keeping the transducer along the long axis of diaphysis, from greator trochanter to lateral condyle excluding the epiphysis.

- Abdominal circumference - For AC, outer circumference of fetal abdomen was taken in transverse section at the level of stomach and intrahepatic portion of umbilical vein.

\section{Fetal weight was calculated using Hadlock formula} $\log _{10}($ EFW $>)=1.4787$ -

$0.003343 \mathrm{ACxFL}^{2} 0.001837 \mathrm{BPD}_{2}+0.0458 \mathrm{AC}+0.158 \mathrm{FL}$

This Estimated fetal weight along with amniotic fluid volume and maternal blood pressure status were then assessed and compared with the reference values for the gestational age (table 1) [19]. The fetus with EFW below the normal range for a gestational age with abnormal Umbilcal Artery PI (PI $>95^{\text {th }}$ centile for the gestatinal age) were considered IUGR.

Table-1[19]

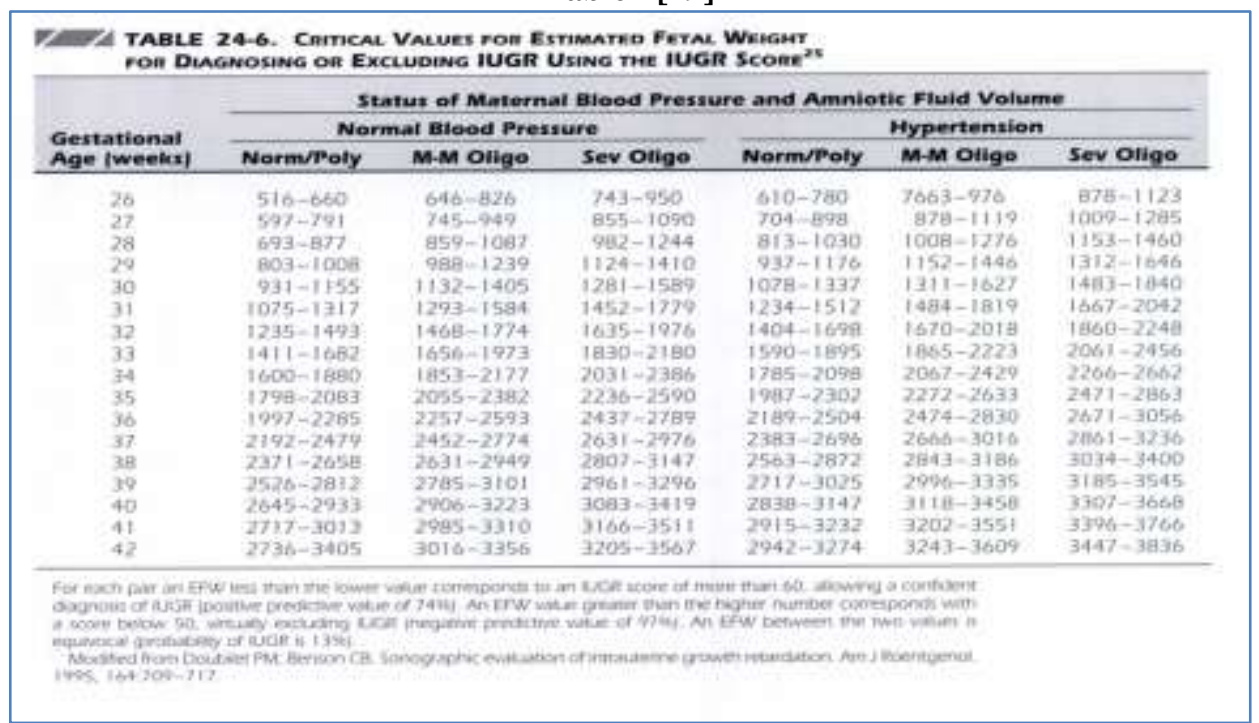


Vijay K Verma et al., Sch J App Med Sci, August, 2020; 8(8): 1949-1958

\section{Doppler study}

Image directed colour and pulsed Doppler study of umbilical artery and aortic isthmus was performed using convex transabdominal transducer. The scanning plane was adjusted and the angle between the ultrasound beam and direction of blood flow was kept as close to $0^{\circ}$ as possible. The sample volume was adjusted to include as much of the lumen as possible without including vessel wall. All the measurements were taken in the absence of fetal movements.

Assessment of Umbilical Artery Doppler waveform was performed by focusing a free floating segment of umbilical cord [20] and placing the Doppler ultrasound gate in the segment, keeping insonation angle close to $0^{\circ}$.

Fetal aortic isthmus was assessed in longitudinal aortic arch view and the ultrasound gate was placed just beyond the origin of left subclavian artey.

For each examination, the following Doppler parameters were assessed -

- Peak systolic velocity (PSV)

- End diastolic velocity (EDV)

- Systolic-to-diastolic (S/D) ratio = PSV/EDV

- Resistive index $(\mathrm{RI})=(\mathrm{PSV}-\mathrm{EDV}) / \mathrm{EDV}$

- Pulsatility index $(\mathrm{PI})=(\mathrm{PSV}-\mathrm{EDV}) / \mathrm{Mean}$ velocity
For assessing the flow velocity pattern of aortic isthmus and to determine the direction of isthmic diastolic blood flow, a semi-qualitative parameter called, Isthmic Flow Index(IFI) was calculated, using the following formula -

- Isthmic flow index $=(\mathrm{PSV}+\mathrm{EDV}) / \mathrm{PSV}$

\section{IFI can have following patterns -}

Type I (IFI >1) antegrade flow in both systole and diastole .Index will increase with increase in volume of diastolic forward flow.

Type II (IFI=1) absent diastolic flow.

Type III (IFI 0-1) predominant antegrade flow in systole with some reversal of diastolic flow, Closer the index to 0 , more is the retrograde diastolic flow.

Type IV $(\mathrm{IFI}=0)$ equal antegrade and retrograde flow. Type V $(\mathrm{IFI}<0)$ forward systolic flow is decreased and retrograde flow during diastole is increased resulting in net retrograde flow through isthmus.

\section{Statistical method}

Statistical analysis was performed in MS Excel spreadsheet using SPSS 19.0. Doppler parameters including velocities and impedance indices were assessed against normal reference ranges using both $95^{\text {th }}$ and $5^{\text {th }}$ centile as cut-off for abnormal values and were analyzed by using unpaired t-test and Pearson's Chisquare test, as indicated. The predictive value of the Aortic isthmus Doppler parameters in assessing IUGR was estimated by using sensitivity, specificity and predictive values.

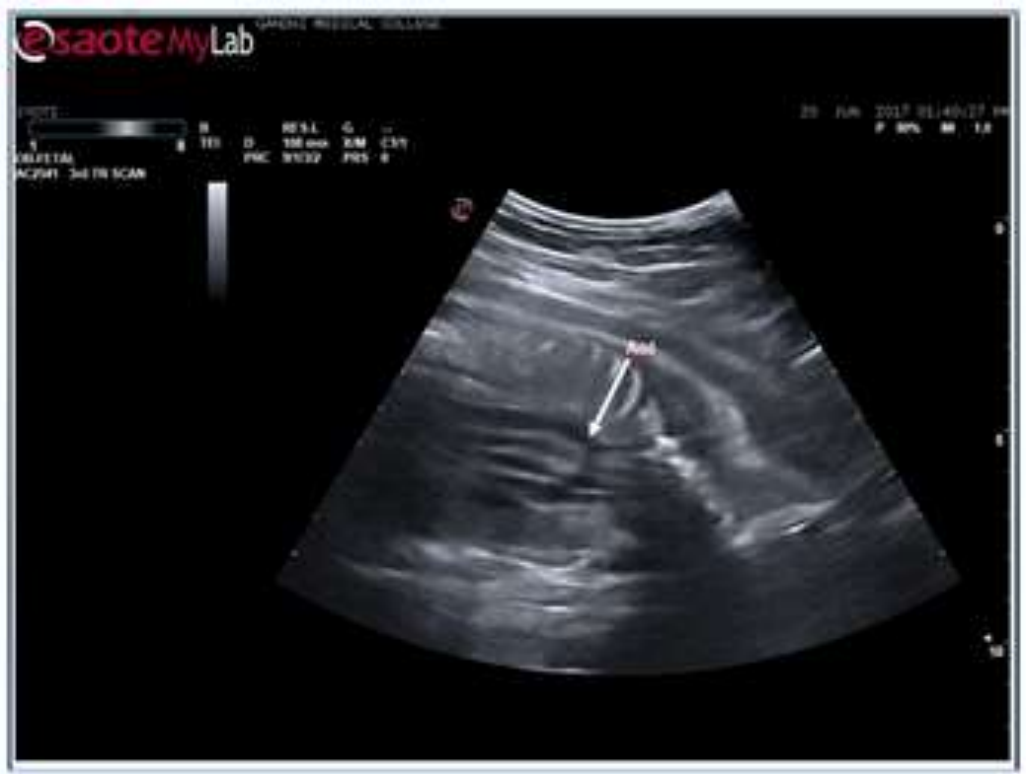

Fig-1: Ultrasound image showing the longitudinal view of aortic arch with the asterisk indicating the position of Aortic isthmus just distal to the origin of left subclavian artery 


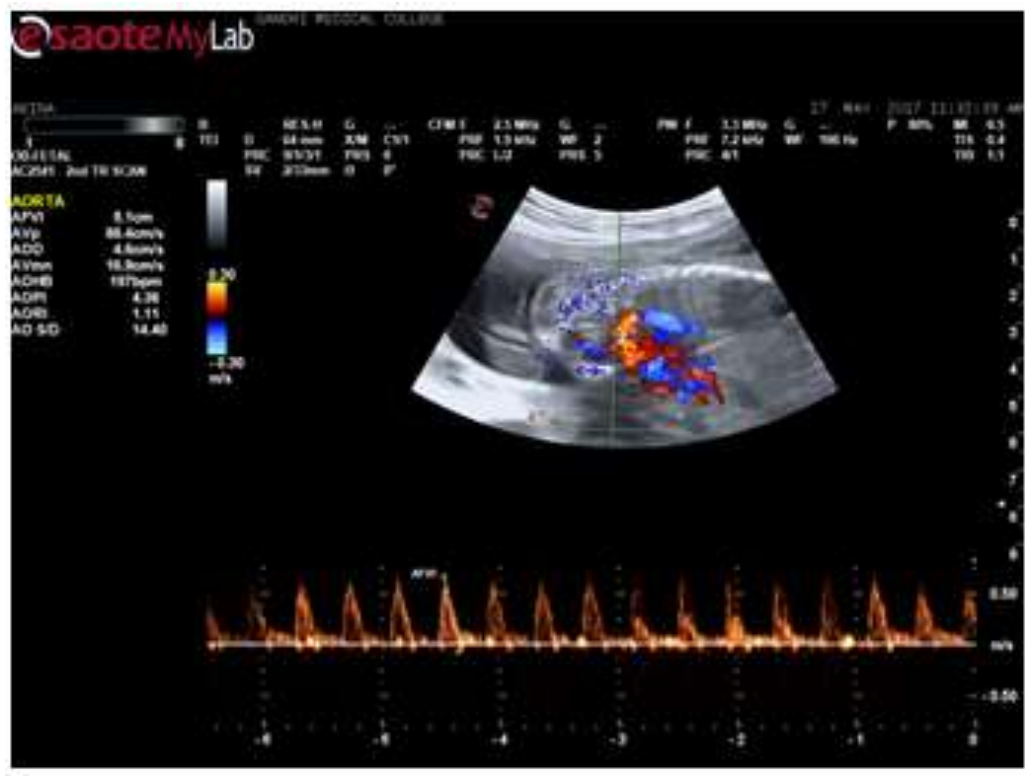

Fig-2: Ultrasound image showing the normal pulsed Doppler waveforms of Aortic Isthmus with antegrade diastolic flow

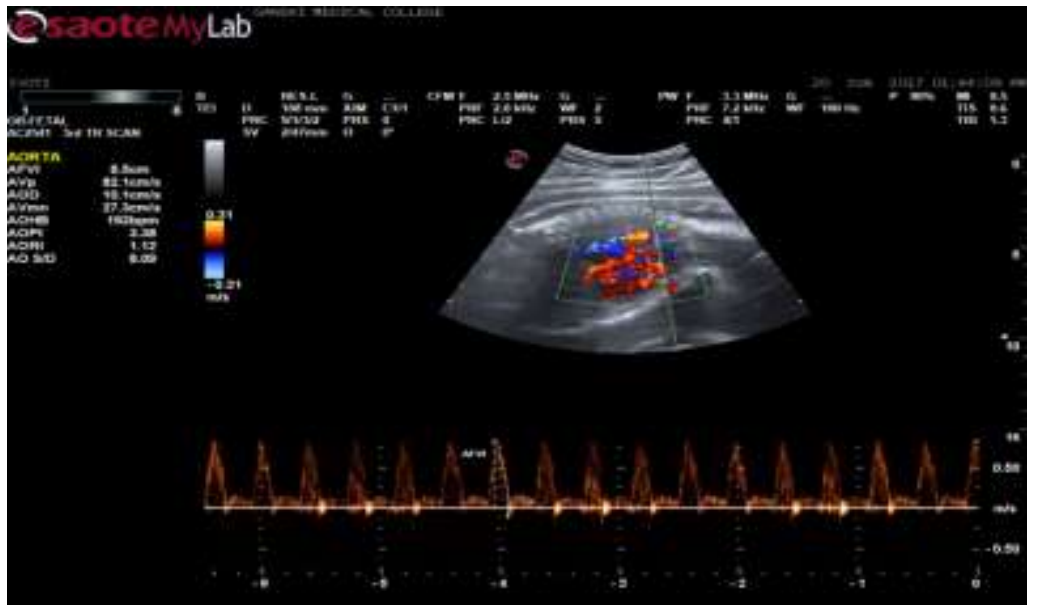

Fig-3: Ultrasound image showing the normal pulsed Doppler waveforms of Aortic Isthmus with a small end-systolic reversal however diastolic flow was forward

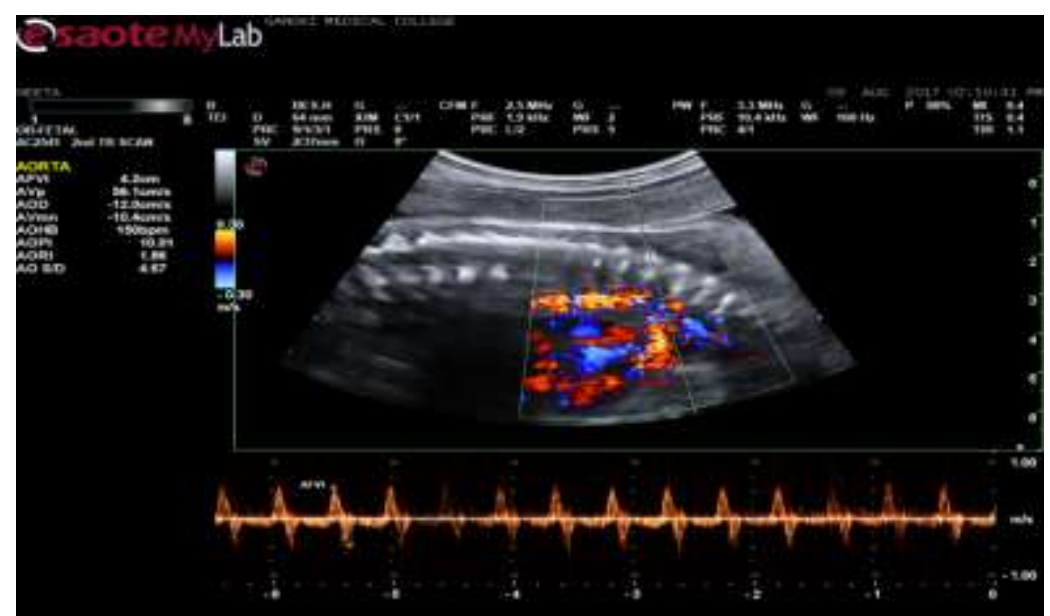

Fig-4: Ultrasound image of Aortic isthmus in longitudinal arch view showing retrograde pulsed Doppler flow

\section{RESULT}

Demographic data, risk factors, ultrasound findings along with Doppler characteristics of cases and controls are described. There was no statistical difference in maternal age and gestational age in between cases and controls at the time of diagnosis. 
Table-02: Distribution of Maternal Age in cases and controls

\begin{tabular}{|c|c|c|}
\hline Number of controls n (\%) & Number of cases n (\%) & Age (years) \\
\hline $17(34 \%)$ & $10(20 \%)$ & $20-25$ \\
\hline $28(56 \%)$ & $26(52 \%)$ & $26-30$ \\
\hline $5(10 \%)$ & $13(26 \%)$ & $31-35$ \\
\hline 0 & $1(2 \%)$ & $>=36$ \\
\hline 50 & 50 & Total \\
\hline
\end{tabular}

Highest incidence of risk factor was found in 26-30 years of age group comprising of $52 \%$ of cases. Median age of pregnant females in both the case and control cohort was 28 years, with a range from 20 to 36 years of age.

Table-03: Distribution of clinical and Ultrasound findings in cases with respect to Maternal Age

\begin{tabular}{|l|l|l|l|l|l|}
\hline IFI $<1$ & Oligohydramnios & BOH & Preeclampsia n (\%) & Previous IUGR n (\%) & $\begin{array}{l}\text { Maternal } \\
\text { Age(years) }\end{array}$ \\
\hline $5(10 \%)$ & $9(18 \%)$ & 0 & $4(8 \%)$ & 0 & $20-25$ \\
\hline $17(34 \%)$ & $21(42 \%)$ & $3(6 \%)$ & $14(28 \%)$ & $5(10 \%)$ & $26-30$ \\
\hline $7(14 \%)$ & $10(20 \%)$ & $1(2 \%)$ & $8(16 \%)$ & $4(8 \%)$ & $31-35$ \\
\hline 0 & $1(2 \%)$ & 0 & $1(2 \%)$ & 0 & $>=36$ \\
\hline 29 & 41 & 4 & 27 & 9 & Total \\
\hline
\end{tabular}

Risk factors and ultrasound findings were most commonly seen in cases above 26 years of age. Most common risk factor was Preeclampsia found in 27 cases, out of which 14 cases were of 26-30 years age group. 17 out of 29 fetuses with IFI $<1$ were found in the maternal age group of 26-30 years.

Table-04: Demographic and obstetric data in cases with respect to antegrade and retrograde flow in AoI:

\begin{tabular}{|l|l|l|}
\hline Retrograde(IFI<1) (n=29) & $\begin{array}{l}\text { Antegrade(IFI>1) } \\
(\mathbf{n = 2 1})\end{array}$ & Risk factors \\
\hline $28(20-33)$ & $28(22-36)$ & Maternal Age(years, Median(range) $)$ \\
\hline $17(58.62 \%)$ & $10(47.62 \%)$ & Preeclampsia (n \%) \\
\hline $29(26-34)$ & $30(26-35)$ & GA at Diagnosis (weeks,median (range) \\
\hline $27(93.1 \%)$ & $14(66.6 \%)$ & Oligohydramnios \\
\hline $21(72.41 \%)$ & $10(47.62 \%)$ & Abnormal Umbilical artery PI $>95^{\text {th }}$ centile for GA \\
\hline $13(44.83 \%)$ & $4(19.05 \%)$ & AREDV in UA \\
\hline
\end{tabular}

Out of the 50 cases, 29 fetuses had IFI value less than 1 suggesting reversed isthmic diastolic blood flow and 21 had forward flow with IFI more than 1. As per the previously described IFI types, all the fetuses with reversed isthmic diastolic flow had IFI type III while rest of the cases and the control cohort had IFI type I. Oligohydramnios was found in 41/50(82\%) of cases and $7 / 50(14 \%)$ of controls. It was found significantly more in cases with reverse isthmic diastolic flow $(27 / 29,93.1 \%)$ as compared to cases with forward isthmic diastolic flow $(14 / 21,66.6 \%)$.

Table-05: Distribution of AoI Doppler indices in cases and controls

\begin{tabular}{|l|l|l|l|}
\hline P- value & Control & Cases & Doppler Indices \\
\hline $\mathrm{P}>0.05$ & $78.91+/-16.65$ & $79.252+/-22.97$ & PSV \\
\hline $\mathrm{P}<0.0001$ & $0.8086+/-0.099$ & $1.1354+/-0.23$ & RI \\
\hline $\mathrm{P}=0.0002$ & $2.6154+/-1.064$ & $7.5392+/-8.80$ & PI \\
\hline $\mathrm{P}<0.0001$ & $14.872+/-9.22$ & $-2.396+/-10.36$ & EDV \\
\hline
\end{tabular}

Mean values of aortic isthmus Doppler indices including PSV, EDV, RI and PI of the cases were compared with control. Mean value of PSV and EDV in cases was 79.252(+/-22.97,P>0.05) and -2.396(+/$10.36, \mathrm{P}<0.0001)$ respectively, and in controls was 78.919(+/-16.65) mean PSV and 14.872(+/-9.22) mean EDV; EDV of the cases was found to be significantly lower $(\mathrm{P}<0.0001)$ than that of control cohort. Also,
Mean RI value in case cohort was $1.1354(+/-0.23)$ as compared to $0.8086(+/-0.099)$ in control cohort $(\mathrm{P}$ value $<0.0001)$ and PI values was $7.5392(+/-8.80)$ in cases and 2.6154(+/- 1.064) in controls ( $\mathrm{P}$-value $=$ 0.0002) signifying that Mean RI and PI were significantly higher in case cohort as compared to control cohort . 
Table-06: Distribution of AoI Doppler indices in cases with antegrade and retrograde flow:

\begin{tabular}{|l|l|l|l|}
\hline P- value & Retrograde $(\mathbf{n = 2 9})$ & Antegrade $(\mathbf{n}=\mathbf{2 1})$ & Doppler Indices \\
\hline $\mathrm{P}>0.05$ & $81.98+/-22.55$ & $75.4+/-23.559$ & PSV \\
\hline $\mathrm{P}=0.0004$ & $1.2286+/-0.24$ & $1.0066+/-0.143$ & RI \\
\hline $\mathrm{P}=0.0055$ & $10.43+/-10.69$ & $3.547+/-1.07$ & PI \\
\hline $\mathrm{P}<0.0001$ & $-9.806+/-5.86$ & $7.838+/-5.02$ & EDV \\
\hline
\end{tabular}

Also, in case cohort, fetuses with retrograde flow through aortic isthmus had significant higher values of PI and RI as compared to fetuses with antegrade flow ( $\mathrm{p}$ value $<0.05$ ).
13/29 (42.83\%) cases with reversed isthmic diastolic flow had associated AREDV in the umbilical artery.

$7 / 50(14 \%)$ cases had retrograde AoI flow while the umbilical artery Doppler indices were normal.

Table-07: Predictive value of Aortic isthmus Doppler indices in IUGR fetuses

\begin{tabular}{|c|c|c|c|c|c|c|c|c|c|}
\hline \multicolumn{2}{|c|}{ Predictive value } & \multirow{2}{*}{$\begin{array}{c}\text { Specificity } \\
\text { d/d+b }\end{array}$} & \multirow{2}{*}{$\begin{array}{c}\text { Sensitivit } \\
\mathbf{y} \mathbf{a} / \mathbf{a}+\mathbf{c}\end{array}$} & \multicolumn{4}{|c|}{ No. of findings } & \multirow{2}{*}{$\begin{array}{l}\text { Doppler } \\
\text { characteristics }\end{array}$} & \multirow[t]{2}{*}{ S. No. } \\
\hline Negative & Positive & & & $\begin{array}{l}\text { FN } \\
\text { (c) }\end{array}$ & $\begin{array}{l}\text { TN } \\
\text { (d) }\end{array}$ & $\begin{array}{l}\text { FP } \\
\text { (b) }\end{array}$ & $\begin{array}{l}\text { TP } \\
\text { (a) }\end{array}$ & & \\
\hline $61.9 \%$ & $79.31 \%$ & $68.42 \%$ & $74.19 \%$ & 8 & 13 & 6 & 23 & $\begin{array}{l}\text { Retrograde AoI } \\
\text { flow }(\mathrm{IFI}<1)\end{array}$ & 1. \\
\hline $70.58 \%$ & $78.78 \%$ & $63.15 \%$ & $83.87 \%$ & 5 & 12 & 7 & 26 & $\begin{array}{l}\text { AoI PI }>95^{\text {th }} \\
\text { centile for GA }\end{array}$ & 2. \\
\hline
\end{tabular}

The fetuses were followed up at birth and 31 out of 50 cases suspected to have IUGR were found to have birth weight less than 2SD below the mean reference values. P-value of $<0.05$ was considered to be significant.

Retrograde flow through aortic isthmus was found to be $74.19 \%$ sensitive and $68.42 \%$ specific with PPV of $79.31 \%$ and NPV of $61.9 \%$.

Abnormal PI values (PI $>95^{\text {th }}$ centile for gestational age) in aortic isthmus was found to be $83.87 \%$ sensitive and $63.15 \%$ specific in predicting IUGR with PPV of $78.78 \%$ and NPV of $70.58 \%$.

Chi square test show significant association (Pvalue $=0.003042$ ) of retrograde flow through Aortic isthmus with intrauterine growth restriction.

\section{DisCUSSION}

Various studies [1-17, 20-22] have described a strong association of retrograde flow through aortic isthmus with the IUGR, our study too confirms this observation. There were some cases who had reverse isthmic diastolic blood flow although the umbilical artery diastolic flow was forward, implying that Doppler study of flow velocity patterns of aortic isthmus can detect changes prior to those occurring in UA in IUGR.

Among the case cohort, 29 fetuses were classified as having AoI IFI Type III, which according to the definition described earlier, corresponds to retrograde flow through aortic isthmus. On the other hand, all fetuses in the control cohort had antegrade isthmic flow corresponding to IFI type 1. Also, PI and RI values of aortic isthmus and umbilical artery in case cohort were found to be significantly higher as compared to control cohort.

On comparing the Doppler indices of aortic isthmus and umbilical artery, it was found that the Umbilical artery PI values were higher in fetuses with retrograde aortic isthmic blood flow than in those with antegrade flow. Also, 13/18(42.83\%) fetuses with absent/reversed EDV in UA had retrograde AoI flow, suggesting that during severe placental insufficiency, compensatory mechanisms starts and there occurs redistribution of blood flow to more vital organs like brain and heart leading to reversal of blood flow through aortic isthmus.

AoI PI values were also found to be significantly higher in cases with IUGR regardless of the severity, suggesting that during placental insufficiency early adaptive changes can be reflected by it before hemodynamic decompensation begins.

Many studies have explored the role of AoI Doppler in IUGR fetuses and have found significant correlation, our study also agrees to their observations. But, some studies found no significant difference in the incidence of adverse perinatal outcome and flow velocity profile of aortic isthmus, yet they studied a small IUGR cohort so the findings need to be assessed further. Their findings are summarized as below- 
Vijay K Verma et al., Sch J App Med Sci, August, 2020; 8(8): 1949-1958

\begin{tabular}{|c|c|c|c|c|}
\hline FINDINGS & $\begin{array}{l}\text { STUDIED } \\
\text { PARAMETER }\end{array}$ & $\begin{array}{l}\text { NUMBER Of } \\
\text { CASES }\end{array}$ & STUDY & $\begin{array}{l}\text { S. } \\
\text { No }\end{array}$ \\
\hline $\begin{array}{l}\text { 1) Significant correlation }(\mathrm{P}<0.001) \text { between } \\
\text { retrograde flow and adverse perinatal outcome. } \\
\text { 2) AoI-PI }>95^{\text {th }} \text { centile in } 41 \% \text { of cases which was } \\
\text { significantly associated with adverse perinatal } \\
\text { outcome. } \\
\text { 3) } 5 \text { IUGR fetuses were longitudinally followed, out } \\
\text { of which } 4 \text { developed retrograde flow in AoI prior to } \\
\text { appearance of changes in ductus venosus. }\end{array}$ & $\begin{array}{l}\text { - AoI Impedance } \\
\text { indices (PI, RI) } \\
\text { - AoI PSV, EDV } \\
\text { - AoI IFI }\end{array}$ & $\begin{array}{l}\text { 51 IUGR cases } \\
\text { studied } \\
\text { prospectively }\end{array}$ & $\begin{array}{l}\text { Del Rio M et } \\
\text { al. }\end{array}$ & 1. \\
\hline $\begin{array}{l}\text { Net retrograde blood flow associated with } \\
\text { neurodevelopmental deficit, Relative risk }=2.05 \text {. }\end{array}$ & AoI-IFI & $\begin{array}{l}\text { 44 IUGR fetuses, } \\
\text { prospectively }\end{array}$ & $\begin{array}{l}\text { Fouron et al. } \\
\text { [26] }\end{array}$ & 2. \\
\hline Reversal of flow in AoI appeared earlier than in DV. & $\begin{array}{l}\text { - AoI-IFI } \\
\text {-EDV of AoI and } \\
\text { DV }\end{array}$ & $\begin{array}{l}31 \text { IUGR studied } \\
\text { prospectively }\end{array}$ & $\begin{array}{l}\text { Rizzo et } \\
\text { al.[18] }\end{array}$ & 3. \\
\hline $\begin{array}{l}\text { AREDV was more frequently found in AoI (absent } \\
28 \% \text {, reversed } 41 \% \text { ) as compared to the UA (absent } \\
20 \% \text {, reversed } 19 \% ; \mathrm{p}<0.0001 \text { ) }\end{array}$ & $\begin{array}{l}\text {-Reversal of flow in } \\
\text { EDV of UA and AoI }\end{array}$ & 100 IUGR fetuses & $\begin{array}{l}\text { Sonessan SE } \\
\text { et al. }[23]\end{array}$ & 4. \\
\hline $\begin{array}{l}\text { Significant high Mean AoI-PI value in SGA fetuses } \\
\text { than in controls }(14.6 \text { vs. } 5.1 \%, \mathrm{p}<0.01)\end{array}$ & AoI-PI and DV-PI & $\begin{array}{l}\text { 178 SGA and } 178 \\
\text { AGA fetuses }\end{array}$ & $\begin{array}{l}\text { Cruz } \\
\text { Martinez R } \\
\text { et al. [24] }\end{array}$ & 5. \\
\hline AoI PSV and EDV significantly less in IUGR fetuses & AoI-PSV and EDV & $\begin{array}{l}74 \text { IUGR and } 71 \\
\text { AGA }\end{array}$ & $\begin{array}{l}\text { Karakus et } \\
\text { al. [14] }\end{array}$ & 6. \\
\hline $\begin{array}{l}\text {-AoI PI values were comparable in both SGA fetuses } \\
\text { and in controls. } \\
\text { - Retrograde flow in AoI did not predate changes in } \\
\text { ductus venosus in IUGR fetuses }\end{array}$ & & $\begin{array}{l}72 \text { AGA , } 48 \text { SGA } \\
\text { and } 10 \text { IUGR } \\
\text { fetuses }\end{array}$ & $\begin{array}{l}\text { Kennelly et } \\
\text { al. [25] }\end{array}$ & 7. \\
\hline $\begin{array}{l}\text { 1)Significant association of retrograde flow in AoI } \\
\text { with IUGR } \\
\text { 2)Significantly high Mean AoI-PI value in cases than } \\
\text { in controls ( } 7.5 \text { vs. } 2.6, p<0.001 \text { ) } \\
\text { 3) } 7 \text { fetuses with retrograde AoI EDV had normal UA } \\
\text { Doppler indices. }\end{array}$ & $\begin{array}{l}\text {-AoI- IFI and PI } \\
\text {-UA EDV and PI }\end{array}$ & $\begin{array}{l}50 \text { cases and } 50 \\
\text { controls }\end{array}$ & Our Study & 7. \\
\hline
\end{tabular}

Experimental [7] studies in chronic hypoxic models have shown that in cases with placental insufficiency, retrograde flow in AoI can occur prior to appearance of abnormality in UA Doppler indices, while some studies [22] have reported consistent association of retrograde blood flow in aortic isthmus with the absent/reversed EDV in the UA. Our study had some cases with retrograde isthmic diastolic blood flow that were having normal umbilical artery Doppler indices.

The observation in our study can be explained by acknowleding the role of AoI in fetal circulation. During fetal life, brain and upper half of body are supplied by left ventricular output whereas the lower half and placenta are perfused by blood from right ventricle reaching via ductus arteriosus. The AoI acts like a junction between the two vascular systems and so the characteristics of flow in it indicate the balance between their net impedances. Accordingly, in conditions of progressive placental insufficiency, the blood flow redistribution can be demonstrated earlier in AoI. Sonessan SE et al. [18] studied 100 fetuses with abnormal UA- PI and found that absent/reversed EDV was more frequently seen in AoI than in UA. Rizzo et al. [18] and Del Rio M et al. [3] studied characteristics of AoI and Ductus venosus Doppler in IUGR fetuses and showed that abnormal velocity waveforms appear earlier in AoI than in DV. Del Rio et al. [3] found no significant correlation of MCA Doppler indices and perinatal outcome.

As described by previous studies [5-9] during placental insufficiency adaptive vascular changes occurs which cause increase in placental vascular resistance together with vasodilatation in cerebral vasculature, leading to increase flow of oxygenated blood to brain and heart and decrease in antegrade diastolic flow in AoI. As the placental insufficiency worsens, the isthmic diastolic flow further decreases and may disappear or in very severe conditions may become retrograde. Moreover, as the blood flow through AoI is decreasing during diastole, it is likely to reflect the increase in value of Doppler impedence indices in AoI. In our study it was observed that AoI PI value was significantly high in the cases with IUGR regardless of severity. Whether AoI PI can also help in the early detection of fetuses with placental insufficiency needs to be further investigated.

\section{Conclusion}

Present study was conducted to assess the role of AoI Doppler in intrauterine growth restriction on the basis of IFI and PI indices. 
- Preeclampsia was found to be the most common risk factor of IUGR and was found in $27 / 50(54 \%)$ of cases.

- 29 out of $50(58 \%)$ cases had IFI <1, suggesting retrograde blood flow through aortic isthmus. The retrograde isthmic flow was found to be significantly associated with IUGR (pvalue $=0.003042$ ) and a good predictor with sensitivity of $74.19 \%$ and specificity of $68.42 \%$.The PPV and NPV was found to be $79.31 \%$ and $61.9 \%$, respectively.

- AoI PI value above $95^{\text {th }}$ centile was found in 33/50 (66\%) of cases as compared to $12 / 50$ (24\%) controls. Also, in case cohort, fetuses with retrograde flow through AoI had significantly higher values of PI (P-value <0.05) as compared to those with antegrade blood flow, reflecting potential role of abnormal AoI PI values in predicting IUGR.

- 7/50 (14\%) cases with retrograde flow through aortic isthmus had normal flow velocity profile in umbilical artery, suggesting that doppler indices of aortic isthmus can detect hemodynamic changes of IUGR prior to deterioration of umbilical artery Doppler waveforms.

The data suggest a potential role of aortic isthmus Doppler imaging in diagnosing and predicting information regarding intrauterine growth restriction early in its course, thereby aiding clinicians in making timely decision regarding delivery in order to prevent occurrence of any intrauterine injury. However, the data needs to be further assessed using longitudinal studies and randomized management trials to verify that delivery timing based on the Doppler findings can affect outcome of growth restricted fetuses.

\section{REFERENCES}

1. Chander L, Sonal G. Colour Doppler in IUGRWhere are we and where do we go?. The Journal of Obstetrics and Gynecology of India. 2010 Aug 1;60(4):301-11.

2. Kennelly MM, Farah N, Turner MJ, Stuart B. Aortic isthmus Doppler velocimetry:role in assessment of preterm fetal growth restriction.PrenatDiagn.2010May;30(5):395-401.

3. Del Rio M, Martinez JM, Figueras F, Bennasar M, Olivella A, Palacio M, Coll O, Puerto B, Gratacós E. Doppler assessment of the aortic isthmus and perinatal outcome in preterm fetuses with severe intrauterine growth restriction. Ultrasound in Obstetrics and Gynecology: The Official Journal of the International Society of Ultrasound in Obstetrics and Gynecology. 2008 Jan;31(1):41-7.

4. Fouron JC, Zarelli M, Drblik P, Lessard M. Flow velocity profile of the fetal aortic isthmus through normal gestation. Am JCardiol.1994Sep!;74(5):483-6.

5. Figueras F, Benavidas A, Del Rio M, Crispi F,
Eixarch E, Martinez JM, Hemandez Andrade E, Gratacos E. Monitoring of fetuses with intrauterine growth restriction: longitudinal changes in ductus venosus and aortic isthmus flow. Ultrasound Obstet Gynecol. 2009Jan; 33(1):39-43.

6. Acharya G, Tronnes A, Rassanen. Aortic isthmus and cardiac monitoring of the growth-restricted fetus. J Clin Perinatol. 2011Mar; 38(1):113-25.

7. Bonnin P, Fouron JC, Teyssier G, Sonessan SE, Skoll A. Quantitative assessment of circulatory changes in the fetal aortic isthmus during progressive increase to umbilical blood flow. Circulation. 1993; 88:216-222.

8. Fouron JC, Teyssier G, Shalaby L, Lessard M, Van Doesburg NH. Fetal central blood flow alterations in human fetuses with umbilical artery reverse diastolic flow. Am JPerinatol; 10:197-207.

9. M akkikallio K, Jouppila P, R as anen J. Retrograde net blood flow in the aortic isthmus in relation to human fetal arterial and venous circulations. Ultrasound Obstet Gynecol. 2002; 19:147-152.

10. Patton DJ, Fouron JC. Cerebral arteriovenous malformation: prenatal and post-natal central blood flow dynamics. Pediatr Cardiol. 1995; 16:141-144.

11. Brantberg A, Sonessan SE. Central arterial hemodynamics in small-for-gestational-age fetuses before and during maternal hyperoxygenation: A Doppler velocimetric study with particular attention to the aortic isthmus. Ultrasound Obstet Gynecol. 1999; 14:237-243.

12. Del Rio M, Martinez JM, Lopez M, Gomez O, Puerto B. Refernce ranges for Doppler parameters of the fetal aortic isthmus during the second half of pregnancy. Ultrasound Obstet Gynecol. 2006; 28:71-76.

13. Zielinsky P, Frajndlich R, Nicoloso LH, Manica JLL, Piccoli AL Jr, de Morais MR, Bender L, Silva J, Pizzato P, Naujorks A: Aortic isthmus blood flow in fetuses of diabetic mothers. Prenat Diagn. 2011; 31:1176-1180.

14. Karakus R, Ozgu-Erdnic AS, Esercan A, Dogan MM: Doppler assessment of the aortic isthmus in intrauterine growth-restricted fetuses. UltrasoundQ. 2015; 31:170-174.

15. Baschat AA, Gembruch U, Weiner CP, and Harman CR. Qualitative venous Doppler waveform analysis improves prediction of critical perinatal outcomes in premature growth-restricted fetuses. Ultrasound Obstet Gynecol. 2003; 22:240-245.

16. Garcia-Canadilla P, Rudenick PA, Crispi F, CruzLemini M, Palau G, Camara O, Gratacos E, Bijens BH: A computational model of the fetal circulation to quatify blood redistribution. PLoS Comput Biol. 2014; 10:e1003667.

17. Fouron J-C,Skoll A, Sonesson S-E, Pfizenmaier M, Jaeggi E, Lessard M:Relationship between flow through the fetal aortic isthmus and cerebral oxygenation during acute placental circulatory insufficiency in ovine fetuses. AmJ Obstet Gynecol. 1999; 181:1102-1107. 
18. Rizzo G, Capponi A, Vendola M, Pietrolucci ME, Arduini D: Relationship between aortic isthmus and ductus venosus waveforms in severe growth restricted fetuses. PrenatDiagn. 2008; 28:10421047.

19. Diagnostic medical sonography-A guide to clinical practice. Mimi C. Berman, Harris L. Cohen. $2^{\text {nd }}$ edition.

20. Mari G, Hanif F, Kruger M. Sequence of cardiovascular changes in IUGR in pregnancies with and without preeclampsia. Prenat Diagn. 2008; 28:377-383.

21. The Aortic Isthmus: A significant yet Underexplored Watershed of the fetal circulation. Tynan D, Alphonse J, Henry A, Welsh AW, Ruskamp J, Fouron JC, Gosselin J, Raboisson MJ, Infante-Rivard C, Proulx F.Reference values for an index of fetal aortic isthmus blood flow during the second half of pregnancy. Ultrasound
Obstet Gynecol. 2003 May; 21(5):441-4.

22. Sonessan SE, Fouron JC. Doppler velocimetry of the aortic isthmus in human fetuses with abnormal velocity waveforms in the umbilicak artery. Ultrasound Obstet Gynecol.1997; 10:102.107-111.

23. Cruz-Martinez R, Figueras F, Hernández-Andrade E, Oros D, Gratacós E: Changes in myocardial performance index and aortic isthmus and ductus venosus Doppler in term, small-for-gestational age fetuses with normal umbilical artery pulsatility index. Ultrasound Obstet Gynecol. 2011; 38:400405.

24. Kennelly MM, Farah N, Hogan J, Reilly A, Turner MJ, Stuart B: Longitudinal study of aortic isthmus Doppler in appropriately grown and small-forgestational-age fetuses with normal and abnormal umbilical artery Doppler. Ultrasound Obstet Gynecol. 2012; 39:414-420. 